University of Montana

ScholarWorks at University of Montana

Spring 2013

\title{
The Protectors and the Protected: What Regulators and Researchers Can Learn from IRB Members and Subjects
}

\author{
Ann Freeman Cook \\ University of Montana - Missoula, ann.cook@umontana.edu \\ Helena Hoas \\ University of Montana - Missoula, helena.hoas@umontana.edu \\ Jane Clare Joyner \\ US Department of Veterans Affairs
}

Follow this and additional works at: https://scholarworks.umt.edu/psych_pubs

Part of the Psychology Commons

Let us know how access to this document benefits you.

\author{
Recommended Citation \\ Cook, Ann Freeman; Hoas, Helena; and Joyner, Jane Clare, "The Protectors and the Protected: What \\ Regulators and Researchers Can Learn from IRB Members and Subjects" (2013). Psychology Faculty \\ Publications. 9. \\ https://scholarworks.umt.edu/psych_pubs/9
}

This Article is brought to you for free and open access by the Psychology at ScholarWorks at University of Montana. It has been accepted for inclusion in Psychology Faculty Publications by an authorized administrator of ScholarWorks at University of Montana. For more information, please contact scholarworks@mso.umt.edu. 


\title{
The Protectors and the Protected: What Regulators and Researchers Can Learn from IRB Members and Subjects
}

\author{
Ann Freeman Cook ${ }^{1 *}$, Helena Hoas ${ }^{1}$, and Jane Clare Joyner ${ }^{2}$ \\ 1) The University of Montana, Missoula \\ 2) Attorney, Washington, DC \\ *Correspondence concerning this article should be addressed to Ann Freeman Cook, National Rural Bioethics Project, \\ Department of Psychology-Corbin 341, The University of Montana, Missoula, MT 59812-7397. \\ Email: ann.cook@umontana.edu
}

Acknowledgments. Jane Clare Joyner, a nurse-attorney, is a Deputy Assistant General Consul in the Office of the General Counsel, U.S. Department of Veterans Affairs, Washington, DC. The opinions expressed in the article are those of the authors and do not reflect those of the U.S. Government or any of its agencies.

Conflicts of interest. The authors report no conflicts.

Abstract. Clinical research is increasingly conducted in settings that include private physicians' offices, clinics, community hospitals, local institutes, and independent research centers. The migration of such research into this new, non-academic environment has brought new cadres of researchers into the clinical research enterprise and also broadened the pool of potential research participants. Regulatory approaches for protecting human subjects who participate in research have also evolved. Some institutions retain their own Institutional Review Boards (IRBs), but Independent IRBs, community hospital IRBs and community-based IRBs also fulfill oversight responsibilities. This article sheds light on this evolving world by discussing the findings gleaned from two studies: a study of the decision making processes used by members who serve on different kinds of IRBs and a study of the decision making processes employed by research participants. The article then discusses how the key findings may inform proposed revisions to the Common Rule.

Key Words. Human subject research, IRBs, clinical trials, protection of human subjects, Common Rule

\section{Introduction: A Changing Landscape}

Before the 1980s, most of the revenue for medical research conducted in the United States came from federal grants. Federal support of basic research led to the first vaccines for the flu, polio, and other childhood diseases. Other medical advances made with federal support include the discoveries of neurotransmitters in the brain, identification of over 20 cancer-related genes, and demonstration that cholesterol levels are linked with potential heart attacks (United States Senate, 2000). Cancer treatment drugs such as Paclitaxel (Taxol, Bristol-Meyers-Squibb, Princeton, NJ) have been developed and clinically tested in humans with funding from the National Cancer Institute (Nader \& Love, 1993). Such federally supported research has been primarily conducted in prestigious academic medical centers such as the Mayo Clinic, Johns Hopkins, Sloan Kettering, Mt. Sinai, and MD Anderson, which are located in large, mostly urban communities. 
The world of clinical research has changed over the last 30 years. Federal funding for research has decreased and industry funding has steadily escalated; by 1991, industry funding outpaced federal funding, and by 2000, 70\% of clinical trials were funded by industry (Bodenheimer, 2000). Some industry research is focused on the development of new or novel drugs, but considerable industry effort is directed toward commercial interests such as extending patents, finding new uses for existing drugs, developing "me-too" drugs to secure a market share, and assessing prescription practices (Kottow, 2009). The change in the research venue is also notable; most clinical research has migrated to nonacademic environments. Although industry funding for clinical research has steadily increased (Congressional Budget Office, 2006), the share of funding for such research conducted in academic medical centers declined from $80 \%$ in 1991 (Klein \& Fleischman, 2002) to $35 \%$ in 2005 (Fisher, 2006), and the decline has continued (Fisher, 2006, 2007; Shuchman, 2007; Sox, 2001). Currently, most industry research, including disease-specific studies as well as genetics and pharmacogenomics research, takes place in settings unaffiliated with academic medical centers, such as private physicians' offices, research institutes, hospitals, and clinics (Chen, Miller, \& Rosenstein, 2003; Klein \& Fleischman, 2002). Federally funded research, such as the Clinical Trials Cooperative Group Program sponsored by the National Cancer Institute, is also moving to community-based settings (National Cancer Institute, 2009).

As the world of clinical research has evolved, so too have the regulatory approaches for protecting those who become research subjects. Institutional review boards (IRBs) serve as key oversight bodies for monitoring research that involves human participants. They are charged with evaluating the risks and benefits, subject selection methods, informed consent process, and methods for protecting privacy and confidentiality. At one time, institutions relied primarily on the work of their own institutionally supported IRBs to fulfill these oversight responsibilities. As a result of recent changes in the structure, setting, and funding of clinical research, although many institutions still retain their own IRBs, new models such as independent IRBs (Macklin, 2008), community hospital IRBs (Hall et al., 2009), and community-based IRBs now perform oversight functions (Jansen, 2005). Many clinical studies that are approved by independent IRBs are conducted in multiple sites and in multiple states (Christensen \& Orlowski, 2005). Even institutions that retain their own IRBs may choose to submit certain kinds of studies to other IRBs rather than performing an in-house review.

Although a robust literature base explores the ethical, legal, and regulatory challenges associated with the protection of human subjects, there is a growing sense that, as Michael Kottow (2009) cautions, "the agility of biomedical research far outstrips the pace of research ethics." He is not alone in his concerns. In an effort to keep pace with the changing times, the U.S. Department of Health and Human Services (HHS) has launched a process to revise the Common Rule. On July 26, 2011, HHS issued an advance notice of proposed rulemaking (ANPRM) to solicit public comments on "how current regulations for protecting human subjects who participate in research might be modernized and revised to be more effective" (U.S. HHS, 2011). The intent behind the rulemaking involves efforts to both enhance protections for subjects and reduce delay and burden for investigators. Section IV of the ANPRM focuses on efforts to improve informed consent and determine what a person needs to know to make an enlightened decision to enroll in a research study. This section highlights a number of broad concerns about current requirements for informed consent forms. For example, question 40 of the ANPRM specifically asks whether informed consent would be improved if regulations included additional requirements regarding the consent process and, if so, what should be required. The comments submitted to HHS become part of the public record. Lodged primarily by researchers and institutional representatives, these comments provide an indication of evolving perspectives within the scientific community. All submitted comments, along with the name of the commenter, can be viewed online (U.S. HHS, 2011). 
Given the changing research environment, it seems useful to examine the perspectives that both "the protectors and the protected" bring to the discussion about informed consent and specifically the kinds of information most important to include in consent forms. This commentary first discusses the findings that emerged from two studies: an exploration of the decision-making processes used by members who serve on different kinds of IRBs (Cook \& Hoas, 2011a, b) and an exploration of the decision-making processes employed by research participants (Cook \& Hoas, 2011c). This discussion sheds light on IRB members' deliberations when reviewing research protocols and the values, needs, and experiences of the research participants. It then presents some of the comments submitted to the ANPRM process in an effort to appreciate the range of opinions within the research community and highlight areas where there may be a lack of agreement about what may be needed to optimize the protection of human subjects.

\section{Research Methodology}

The IRB study and the Research Participant study were funded by the National Science Foundation. Both studies were inductive and contextual in nature (Miles \& Huberman, 1994; Strauss \& Corbin, 1990), an approach well-suited to the exploration of these complex phenomena and relationships. The studies analyze key informant interviews with IRB members and research participants who live in rural and urban settings. The sampling strategy was designed to maximize respondent variation to facilitate examination of information-rich cases, detect patterns spanning differences within and among the various stakeholder cohorts and settings, and optimize confidentiality. To create a national sample for the IRB study, the investigators first identified all IRBs holding a Federal-Wide Assurance Number from the Office of Human Research Protections. IRBs were categorized according to type, and a purposive sample was selected so as to include seven groups or types: IRBs that serve in universities with and without medical schools, IRBs from both rural and urban hospitals, community
IRBs from both rural and urban communities, and for-profit IRBs that typically serve researchers in several states. Once selected, the IRB was contacted via phone or email, and a member was invited to participate in the study. A minimum of four to six key informants were selected from each type of IRB for a total of 40 participants.

To obtain a national sample of research participants, the investigators designed a geographically diverse sample of facilities that engage in health research, including hospitals, clinics, mental health centers, and private practice settings. Healthcare personnel were contacted, given information about the study, and asked to verbally share information about the study with patients or post information about the study in their facilities. Persons interested in participating could then contact the investigators and schedule an interview. The sample of research participants was composed of 33 females and 17 males. The education level of participants was high with $87 \%$ reporting at least some college education. After conducting 50 interviews, no new information was emerging; it was determined that saturation had been achieved and the interview process was suspended.

For both studies, the investigators used semistructured instruments that employed core questions while also allowing for exploration of unanticipated or emerging issues. The interviews were conducted by phone and transcribed verbatim. Most interviews lasted about an hour. With the aid of Atlas.ti software, the data were coded and organized into themes that could then be compared and contrasted. This approach allowed the investigators to obtain "yes" and "no" responses that could be calculated as well as lengthy explanations that showcased the processes for making decisions. Throughout the manuscript, representative quotes are used to provide a general view of the interviewees' perspectives. The interview data obtained from these studies provide a rich repository of insights from those who serve in a regulatory function (IRB members) and those for whom the regulations are designed to protect (human research subjects). Although the authors' prior publications detail each study's research methodology and overall findings, this 
article combines, compares, and contrasts key findings and themes of those two studies. By juxtaposing the words and phrases of those who protect (IRB members) and of those who are protected (research participants), the article attempts to expand awareness and appreciation of where we are and what it might take to foster a system that truly optimizes protection of human subjects through the consideration of all voices and concerns.

\section{Protecting Subjects' Rights and Welfare}

\section{The IRB Perspective}

The findings from the IRB study suggest that IRB members view their responsibility to protect the rights and welfare of human subjects in a very serious light. Indeed, members of all types of IRBs-academic, hospital, community/tribal, and independent—often described their IRB service as a "calling" and as a "mission." Members from all types of IRBs frequently referenced the ethical violations of past studies like Tuskegee and the need to ensure such ethical deviations do not re-occur. Most IRB members described their IRB service as very time intensive, often unappreciated, and at times burdensome, but also very important; they reported that the numbers of studies under review were increasing, study protocols were often complicated, and the decisions they made influenced research conducted in diverse rural and urban populations. Members reported that many hours were expended in the process of carefully reading the materials submitted to the IRB and attending the scheduled meetings. Although the work was described as challenging and difficult, all of the members spoke of its importance and reported that their IRBs "do a good job" (Cook \& Hoas, 2011a, b).

However, the findings from the IRB study also suggested that-despite members' commitment, good intentions, and hard work - efforts to protect human subjects may fall short of the mark. Most IRBs used, as a central strategy for optimizing the protection of human subjects, careful scrutiny and management of the informed consent form. The data showed that this strategy was pursued regardless of the type of IRB. A quote representative of this approach was offered by an IRB member who explained: "The focus is on the form. [There is] little discussion of the context or the process" (academic IRB). Most IRB members viewed the form as an essential tool for ensuring a voluntary and enlightened participant. Explained one IRB member: "Our process is, first it's the member being able to understand, then from the staff point of view, and then we go over it point by point. You can have a good reading level, but not representation of what is going to happen" (independent IRB). Members from other types of IRBs detailed similar approaches to ensure that the form met all technical and regulatory requirements. They offered statements such as: "[IRBs] nitpick every single word throughout the 35 pages" (medical school IRB); and "I don't think we have had hardly a form that hasn't been altered to go to a lower level of readability" (community IRB); and "We strive for understandability and we look for medical jargon ... we have members who are sticklers" (community IRB).

The need to create a consent document that clearly conveys essential information was evidenced when members talked about issues such as assessing risk and benefit. Members offered representative quotes: "So it is the role of the IRB to see risks and benefits and catch risks. With the help of committee members that are knowledgeable about stuff, they catch potential risk and we make changes to the consent form" (medical school IRB). This approach seems to reflect an understanding that the IRB's job is not to design the research study, but to recognize risk and make certain it is accurately conveyed. The following quote sheds light on this perspective: "It is not the job of the IRB to change the study. The IRB's job is to make sure participants have the best chance of understanding the risks" (hospital IRB). As another member explained, "I am not sure how you quantify extent but it is not unusual for us to clarify, tighten, amplify the consent form. I am not sure that we see something that wasn't in the materials as much as clarify and bring it out and clean it up and better convey, make it more understandable" (academic IRB). 
IRB members acknowledged the challenge of developing a consent form that contains all mandated information while still meeting a reading competency level that seemed to be envisioned as somewhere between 4th and 9th grades. Tensions arise with investigators and sponsors who perceive such scrutiny - and often requirements for wordby-word changes - as intrusive and a hindrance to study approval. IRB members acknowledged that the approved forms were probably too long and might not be read by research participants. Members asserted, however, that such careful scrutiny was essential in terms of documenting their regulatory obligations to protect human subjects. The form was seen as a way to underscore the considerable efforts undertaken to ensure that decisions of participants were both voluntary and informed.

In addition to careful management of the consent form, members also explained that they carefully evaluated any compensation provided to the research participant to minimize risks of compensation becoming coercive or unduly influencing a decision to participate. Indeed, all of the members felt they had sufficient guidance and authority to deal with the topic of participant compensation. As one member explained, "When I see participants are going to be paid, that is always a flag to talk about coercion and incentives, especially if it is a vulnerable population" (community IRB). Another reported: "Sometimes we hear they want to give a big bonus and we won't let them do that" (academic IRB). IRB members explained that they were so vigilant about participant compensation because they wanted to ensure that potential participants truly understood and appreciated the risks associated with participating in research and would not be swayed by the prospect of compensation.

\section{The Participant Perspective}

Most of the participants (42 of 50) interviewed for this study reported that they read the informed consent document before enrolling, and most reported that they had been fully informed (Cook \& Hoas, 2011a, b). Few participants reported negative experiences with the informed consent process; most seemed to view the process as routine or as what one could reasonably expect from a medical encounter in a professional setting. As one participant stated, "It had a good setting, good information. She slipped out and let me read it and came back and asked if I had questions" (participant 6).

A series of follow-up questions, however, call into question the extent to which participants truly understood and appreciated the purpose of the consent form, the information it contained, or what it meant to participate in a research study. The data suggest that participants' beliefs and expectations about healthcare may make it difficult for them to absorb key information when trying to make informed decisions about participating in research. Rather than relying on information provided via the consent process or the consent form, participants seemed to make their decisions based on the belief that participation would serve their best interests. Other factors that influenced decision making include beliefs about the trust, skill, and intent of those who conduct research, the legitimacy of the setting, and the socially meritorious purpose of the research. When patients were asked "Why did you enroll in the study?", they uniformly reported that they trusted their doctors and believed that respected, trusted, and skilled clinicians would not suggest enrollment in a clinical trial unless it provided the best option for their care. When asked, "Who invited you to participate?", participants typically referenced the involvement of personal physicians. Said one participant, "My oncologist. ... He said 'Hang on a second.' He said you are perfect candidate for [this] study" (participant 43). Other representative comments include: "My physician suggested it. He is the one that does it" (participant 46); and "[The] doctor who recruited me. I trust him completely and I love the man" (participant 14). Such trust and confidence in the persons conducting the research seemed to limit the extent to which participants could seriously discern the difference between research and treatment or evaluate statements about the risks and benefits of research participation.

In addition to mentioning the confidence entrusted in one's clinician, participants consistently 
explained that a professionally recognized site-like a hospital, clinic, or physician's office-reinforced their assessment of legitimacy and potential benefit. As one participant offered when asked to describe what information was most helpful in terms of making a decision about research participation, "Well, I think it was because it was credible. It wasn't just a piece of paper. It was in the hospital's surgical setting. It was not just something in the mall. And it seemed like there was a benefit and [he] would get more attention. And it was in the hospital" (participant 10). Others explained: "I guess having gone in there and if it had been shady-I would have thought twice. But it was a nice, clean, presentable place. The professional manner and they were thorough and they had the patient rights information. It looked like a doctor's office. They had all the things that I expect from a doctor's office" (participant 3); and "We went out to their office and it was professional. It didn't look like a store front. They had coffee and candy bars and they sit down and talk to you-from the receptionist, nurse, PA or NP, it was all nice. I met with three people during the first visit" (participant 18).

Most participants also expressed support for and confidence in the important work of science, generally believing that medical studies were designed and conducted to benefit both the patient and humankind. Thus, in addition to providing personal benefit to one who enrolls, most participants also alluded to the benefits gained for society, and described hopes that research would find new cures, create miracle drugs, and reduce suffering in generations to come. They spoke of advances that had been made such as the polio vaccine and the treatments for AIDS and cancer. Representative quotes included: "I saw it as an obligation and it may have benefits to someone else" (participant 6); and "The other reason was very strong in my mind was maybe I would be doing something positive for science and for people. I would contribute. That was big in my mind" (participant 14); and "Just to be helpful, to help these peoples' plight and further the research" (participant 37).

Given this multilayered trust that the participants found in the person, the place, and the purpose of research, most seemed disinclined to seriously examine key information in the consent form including the statements of benefits and risks. This was evident when persons responded to a series of questions about risks and benefits including: "What did you see as the benefits of participating, what did you see as the risks of participating and did you see the benefits as outweighing the risks?" When describing their assessment of the risks and benefits of participation, most explained that the benefits outweighed the risks. The data suggest that those who had enrolled in a clinical research study typically overestimated the benefits of participation, noting that it afforded "optimal personal care" and access to what would become the "new gold standard." Participants offered representative statements like: "Well more for less. Better care and a better cure. My treatment would be more complete and there would be less chance of reoccurrence" (participant 47). Another participant reported: "By the time I met with the oncologist and told him I would join, I felt that the whole consent thing had been much ado about nothing. I would either get the gold standard or something they thought was even better. It sounded like a way I could give back with no real risk at all" (participant 49). This perception of personal benefit was evidenced by another participant who explained: "Well, then I started talking myself into it and he [my doctor] said the D-drug would be the new Lipitor, the miracle drug. That sounds so hopeful. . . . So I thought well if it works, I would be right in line and first to get the full treatment" (participant 14). The provision of more time and more tests was often cited as a validation that, upon enrolling in a study, one would receive better care.

The risk statements outlined on the consent forms were generally discounted even when such statements outlined the potential for serious complications. Participants often explained: "I did not see any risks." Many of those who discounted the risk statements on the consent forms believed that a study would not be offered by a trusted source, like one's personal physician, unless the risks were minimal. This perspective was shown by statements like: “Because I don't presume there are any risks. 
They didn't really talk about them" (participant 38); and "At the time, I didn't see it as a risk because I didn't even think to ask.... And I didn't think about it then. I don't remember that I was alerted to any problems. I probably wasn't because I maybe would have hesitated if I had been alerted" (participant 16). Some participants expressed the belief that the government would not allow studies-and doctors would not recommend them-if there were serious risks. As one participate explained: "But I think there is an assumption that you make in a waythat if someone asks you to do this, like if a medical persons asks you-you think they already know the risks are minimal and they would not put you at a great deal of risk. They have your well-being at heart. That is how most people would think. But it may not be true. They are doctors. There is the trust thing" (participant 21).

Even when participants reported that the consent form identified potential risks, they were not sure how to assess the importance or relevance of that information to their personal care. A representative comment is shown by the participant who explained: “I didn't see many risks. The only thing that made it sound like any risk was the blood thinner and maybe you would be less inclined to stop bleeding-or maybe you could lose a lot of blood?" (participant 2). Another explained: "You had to sign a form that said you might have a heart attack. I thought it was a formality-like what you sign before surgery, the form saying you might die. It was just like the legal language thing on the consent forms ... that thing you have on consent forms like being injured. Yeah. I didn't take it seriously" (participant 4). One person noted that the consent form did, in fact, indicate the potential risk of congestive heart failure, but was reassured when "the doctor said congestive heart failure was treatable" (participant 47).

Although consent forms are usually required to include institutional boilerplate information about protocols for privacy and confidentiality, most participants seem to lack a framework for appreciating why those safeguards are required and essential. Thus, this information was also generally disregarded. Participants expressed few concerns about privacy, confidentiality, anonymity, and evolving issues like banking of blood and tissue samples and the potential uses of genetic information. Most did not seem to make distinctions between privacy, confidentiality, and anonymity. Nearly all of the participants (42 of 50) believed that the standards for protection of participants were in place, that medical information was secure, and that their interests and well-being were protected. Explaining their understanding of privacy and confidentiality, participants offered statements like: "It was private. I was the only one. I was the only one in the room" (participant 7) and "Yes. They seem to be careful of how they are handling phone calls and the personal upfront interview" (participant 17). When participating in studies that gathered genetic information, participants were reassured about anonymity when told they would be de-identified by a numbering system and offered explanations like: "I would be assigned a number-that seemed OK" (participant 6). For many patients, concerns about confidentiality and privacy simply did not seem important. This was shown by people who said: "Didn't even consider that" (participant 1 ) and "Yes [adequate protection]. But then I am not paranoid" (participant 5) and "I did think it was OK. They are planning to do video and audio - I had fleeting thoughts about medical records and this mental health problem being on a permanent record for my daughter. But I think everybody has a mental health issue-so I felt fine" (participant 15). Reflecting on implications of participating in a study, a participant explained: "I have no knowledge of what happened to the data over time. And see, foolishly, I didn't think about it" (participant 7). Others explained: "How can people possibly understand that?" (participant 6); and "I think I gave them permission to use information about me" (participant 33).

\section{The Role of Researcher Compensation and Other Commercial Considerations}

\section{The IRB Perspective}

To use a colloquialism, IRB members seem adept at "looking where the light shines." Members 
noted that the regulatory guidance for issues like the content of the informed consent document and protocols for reviewing participant compensation are well developed, and IRBs feel competent to make decisions in such areas. IRB members found it more difficult, however, to resolve an array of other issues that influence their approach to review and, ultimately, the extent to which IRB efforts truly optimize the protection of human subjects. A key issue involves the core mission of the IRB, that is, whose interests should be served? When trying to explain how they approach their decisions, members routinely noted that they faced convergent-and at times even competing-goals. Although the responsibility of protecting human subjects was uniformly acknowledged as a historic and key responsibility, IRB members consistently reported that they are also expected to support the interests of researchers/institutions and help to advance discoveries that benefit society. Indeed, with the exception of one respondent who reported that protection of human subjects was the sole goal of the IRB, the other IRB members were very specific about the expectation and obligation to manage these additional goals. A representative comment about the need to support the interests of peer researchers was explained by a respondent who noted: "It is the dynamic. Like it is hard for doctors to turn one another down" (hospital IRB). Members described the important role that research fulfilled within their institutions and the complications that could ensue if research was not approved. This was noted by a person who explained, "It can be hard to protest too much because the company is paying you. You are supposed to be thinking about the safety of the person but it is hard to divorce the idea of who is paying you" (independent IRB). Discerning the benefits that accrue to society was explained by one participant as a "grey zone, not in the patient's best interests" but "maybe good in the long run?" (hospital IRB).

The formula for balancing what can be experienced as three competing goals (protecting subjects, protecting the interests of researchers/institutions, and helping to advance discoveries) was not welldefined. Members noted that conflicts among these goals can be hard to resolve and that approval of a study is generally based on a majority vote that may not reflect the concerns of dissenting individuals. The tension encountered when trying to balance convergent goals was reflected by comments such as: "I wish we could really protect. I think it [IRB] does primarily, except I am unhappy that the subjects are not protected more" (hospital IRB). Another respondent explained: "There's this tension. The doctors and the scientists will argue that the research is important. The community people might not like it and might feel that it is not really fair to the participants. So there is that tension" (academic IRB). The challenges that accompany the management of "convergent goals" became apparent when IRB members described how they approached three increasingly difficult issues: Evaluation of the purpose of a study, disclosure and evaluation of researcher/institutional compensation, and obtaining awareness of participant needs, values, and expectations. These issues are challenging in part because they are not fully addressed by existing federal regulations or IRB member training. For example, some of the studies under review, mainly industry-funded studies, are designed to answer both scientific and commercial questions, such as development of a "me-too" drug or a change in formulary to extend a patent. The IRB members reported that a review generally focuses on the scientific approach, including the study design, research protocols, and related issues such as safety, risk, and effectiveness. Members may not know about the commercial purposes of a given study and indeed most noted a lack of regulations about their role when assessing the merit of studies that are designed primarily for commercial purposes. Members reported that it was not clear whether the IRB should require submission of clear and transparent information about commercial purposes, if or how such purposes should influence the assessment of a study's scientific merits, whether research participants should be informed of commercial purposes, or how commercial purposes should be evaluated when considering the study's potential benefits to society. These kinds of issues brought to the fore the challenges posed by what was perceived, by 
the vast majority of IRB members, as the need to manage convergent goals. Some suggested that an IRB's exploration of commercial purposes could engender charges of "mission creep," an issue of concern within their institutions or companies. Indicative of the tensions that can emerge when facing this less regulated area of review, members offered representative comments, such as, "Frankly, all of these bazillions of trials are a little tweaked because the patent is running out. All they want is to maintain the patent. So they tweak the drug a little bit, change the formularies or combinations a little, and then that will keep the patent in place. Should we tell the patients that? But the docs, the researchers say no. That's not our business" (hospital IRB). Another member noted, "We have had questions when people are a little uncomfortable about the science-like is this a good study? But there is some other committee that is supposed to look at the science-that is not our turf. So if it is not really beneficial-like some kind of a patent study-we cannot really say much about that" (hospital IRB). The potential impact of disclosing and discussing a commercial purpose was summarized by a member who noted: "It is like there is this fear [among researchers] that if you allow that kind of disclosure, the whole shebang will fall apart. People won't join studies if you give them the whole truth. The trouble is how informed do people have to be? If the study was being conducted to extend a patent-I would not be willing to participate. And I would want to know that. Definitely. So there is intentional dishonesty in omitting information that could sway decisionmaking" (hospital IRB).

Although all IRB members reported that information about the scientific purpose of a study was disclosed to the IRB, most IRB members reported that information about the commercial purpose of a study was not "on the table" (a descriptive often used by IRB members) during the review process. Indeed, members reported that they would not necessarily know if the study involved a commercial purpose such as "tweaking the formulary" of an existing drug so as to extend a patent, developing a derivative drug to obtain a market share, or assessing prescription practices. Others noted that such issues would be recognized but simply not discussed. Some IRB members reported a nagging sense that certain kinds of studies were not necessarily meritorious or truly beneficial to society. Most noted, however, that any consideration of commercial purposes would remain "off the table" until regulatory guidance stipulates otherwise. There seemed to be a sense, among most IRB members, that existing regulations create a floor and a ceiling, leaving limited room for movement. This status seemed to leave some members with an uncomfortable and unresolved moral burden. As one noted, "You get everything approved if you wait long enough. Especially phase IV marketing: It's a lousy drug that sells tremendously well and has nothing to do with science and it is declared as research and ... the physician likes the new drug and starts prescribing it. This marketing is a very large part of the studies for our IRB. You become a cooperator" (independent IRB).

Most IRB members also reported a lack of guidance about researcher and institutional compensation, noting that it was unclear what should be disclosed, to whom, when, or how. Whereas all the IRBs vigorously examine and debate the compensation provided to research participants, most of the IRBs represented in this study did not request or receive detailed information about the study budget and so knew little about the amounts or types of researcher and institutional compensation. Members offered comments such as: "That [compensation for researcher] is not discussed, not discussed at all. It is definitely something that in our environment people don't want to talk about. It is the unknown" (hospital IRB). Another member explained: "Totally taboo. Someday this is coming ... right now you as the investigator gets this much money for entering and your university gets this much and the university likes money" (independent IRB). A member who seemed troubled by the lack of regulations when dealing with researcher compensation explained: "This era of transparency is uncomfortable for an organization that doesn't want that stuff [researcher compensation] known and for the physicians who have had the luxury of a relationship and contact with industry and 
not having to be open with patients about that" (hospital IRB).

The data showed that these two issues-disclosing the commercial purposes of research and disclosing researcher/institutional compensationwere difficult topics for all IRBs, regardless of type. The responses to these issues help to exemplify how the explicit (protecting human subjects) and implicit (protecting interests of researchers) goals that shape the IRBs' mission can become less convergent and more competitive. Members noted that institutional expectations, practices, and pressures can complicate efforts to both support the researcher/institution and at the same time protect the subject. Members of independent or central IRBs explained that an in-depth exploration of researcher compensation would be "bad for business" and "we can't do it unless everyone has to." As one member explained: "I can't remember what it was, where we commented to each other that the way the regulation was written left the door open and didn't leave room for us to make a comment, address the issue. The authority or parameters that we operate under didn't give us room to question. I remember we said the regulations say blah, blah, blah, so we can only do so and so" (independent IRB). Members of hospital IRBs spoke of their professional relationships with peer researchers and the unease associated with asking what seemed like personal questions. A representative comment was: "There are a lot of conflicts of interest for someone with an experimental procedure for the device that they want to put in a patient. And it is their patient. And they get paid for it. But the IRB doesn't do as critical a look at that situation. It is the fox in charge of the hen house. You make a lot of money doing practice-based research. A lot." Another member noted: "It is a tough spot to be in as a nurse. You have to gauge when to speak up. There are repercussions for speaking up-this is a very politically correct organization and the repercussions get back to you. Not politically OK to ask questions about things like disclosure of incentives and you know it" (hospital IRB). Similarly, members of academic IRBs noted that exploring issues associated with researcher/institutional compensation could jeopardize professional relationships and impact issues like tenure or annual personnel evaluations. As one member explained, "The IRB Chair should be tenured and full professor and someone who would be hard to touch. A junior professor couldn't do that. You can't have someone without power" (academic IRB). Another noted that, "If it is important to the $\mathrm{U}$, you find a way to approve it" (academic IRB).

Members were asked if they thought research participants would want to be informed about the commercial purposes of research and about researcher compensation. This question seemed to create a conundrum. Most members reported that they had little knowledge of the values, expectations, beliefs, competencies, and needs of those whom they are charged to protect-the research participants. Members noted the importance of including community members on the IRB to facilitate awareness of participant perspectives, but also acknowledged that it is hard to truly assess the extent to which such involvement truly represents the needs of those who may ultimately participate in research. Some members suspected that participants may well want to be informed of commercial purposes before agreeing to enroll in a study. Indeed, some members reported that they themselves would certainly want to be informed of commercial purposes and researcher compensation before participating in a study. However, such information was not typically viewed as within the purview of most IRBs and so processes for disclosing such information to participants were not in place. As one member noted when offering a summary comment about what should be disclosed and how and why and when, "We don't have a way to asses if we protect human subjects. Everything goes to that point; not even the FDA audit truly looks at the protection. They look at our records. They ask, did you document $A, B$, and C? Not even relevancy is assessed by FDA" (independent IRB).

\section{The Participant Perspective}

To explore how participants view researcher compensation and commercial purposes when enrolling 
in a study, participants were asked a series of questions that included: "Would you want to be informed about researcher compensation?" "Would it matter to you who is paying for or sponsoring the study?" "Would you want to be told if a study was being conducted for a commercial purpose like extending a patent?" "Would that kind of information influence your willingness to be involved?" "Was there anything that came as a surprise or was unexpected when participating in the study?" This series of questions came after participants had a chance to provide a narrative description of their research experience and respond to questions about recruitment, the consent process, their assessment of risk and benefit, and related issues such as the use of resources and their decision-making processes. The questions about purpose and compensation seemed to offer participants a different lens with which to assess their participation. Most seemed quite surprised when asked if they would want to receive information about the compensation provided to researchers or institutions that conduct research. Most had never thought about such compensation, or were completely unaware that such compensation was or could be provided. They offered statements like: “Wow. We didn't know that-they get paid for helping to run these studies? Really?" (participant 47); and "That never entered my mind that it is a possibility. ... It's a new thought to think about compensation. I guess I think the doctor wouldn't get paid" (participant 14); and "But it would not have occurred to me before I learned a little more about research studies in general. And how they are funded. As a patient, it would arouse skepticism. Why are you inviting me? What is your larger purpose?" (participant 19).

Some participants seemed to believe that if the researcher received compensation, the amounts would be minimal. One participant explained: "I don't think I would ask about it. It would feel sort of-not my business. But I would want to know if the researcher was getting compensation and then I would be mad if I didn't. And when there is something like that statement in the consent form - 'the researcher is getting compensated'-I would think it was like $\$ 10-$ not anything big. It wouldn't occur to me. The way it is written, it is like they want you to gloss over it. Not notice it. It is a scary deal. I think about my parents and they are old and don't know about research and could be taken advantage of. And if there's a lot of money, how do they decide what study to suggest?"(participant 4). Another one said: "Oh. Oh my. Well if they get compensation, they are ethically obligated to tell about it. Absolutely. If you think you are signing up for this study and the doc is doing it out of his charitable response to the world that is one thing. But, if he is being paid to run this study that is entirely another" (participant 6).

Most participants $(42 / 50)$ reported that they wanted to know about researcher compensation and that such information could play a role in their decisions to participate. The implications of providing such disclosure were not clear. Although some said that such compensation would not necessarily deter their participation, they also asserted that they should be told in a very clear and transparent manner so that they could make informed choices. Explained one: "People think their physicians are saviors. You saved me from cancer. That's how they want you to see it. I would want to know if they got compensation for running studies. I would want more than the blanket statement" (participant 26). Reflected another: "Docs probably should disclose [what they get], though they don't. They wouldn't want to disclose because they don't want patients to know-it would change their thoughts on it. Some would think the doc wants me on this study because he is making money" (participant 30). Still another explained: "I would feel deceived if someone was getting an enrollment or other incentive and not tell me. It would make a difference who was funding the study. More information should be provided-a statement like the doctor receives compensation for research-it is misleading because you think it is on par with what is happening to you" (participant 8).

Participants also seemed quite surprised when asked if they wanted to be informed about the commercial purposes of a study such as extending patents, developing "me-too" drugs to secure market shares, or assessing prescription practices. Most seemed to believe that clinical research was 
being conducted to further science and so benefit humankind. As one person explained: "I assume it is on the up and up and not so that [the pharmaceutical company] can make a million dollars marketing the drug. Well, it seems to me that if I am in the guinea pig group, I want to make sure it is on the up and up and I am not sacrificing my body for someone's bottom line" (participant 13). Another noted: "I wouldn't think to ask that. I'd never think to ask that. But I would like to know" (participant 20).

Indeed, 45 of the 50 participants asserted that they wanted to be informed about commercial purposes, and most stated that disclosure of such information could influence their decisions about participation in future research. The statements offered were emphatic and descriptive: "The purpose of the study ... yes, I would want to know. And if it was to extend the patent or something like that $-\mathrm{hmmm}$ that's dirty. They should tell about something like that. Not to tell, that does feel deceptive. I wouldn't want to be in that kind of research" (participant 4); and "The full purpose should be disclosed. Otherwise I feel that is dishonest, just playing with words, semantics. The IRB should never approve that kind of consent. And I would lose respect for an IRB that did" (participant 5); and "Extend a patent-hmmm. Yes, I would definitely want to know that. Then they wouldn't be able to do the generic drug. I would want to know absolutely. Absolutely" (participant 14); and "People should absolutely be told if they are trying to extend a patent. That is not to anyone's benefit. There are some good things that pharms come up with - but the bad side is that capitalistic attitude. Absolutely I want to know. Should you know, absolutely. We were not told anything about that" (participant 16); and "Of course. The patient should be told about the purpose and so they can decide" (participant 35).

As participants pondered the questions about disclosure of researcher compensation and commercial purposes, they seemed to reevaluate some of their previously held beliefs about the varied purposes for conducting research and why clinicians may choose to participate. The notion that a clinician might receive payment when conducting research seemed to introduce the notion that there could also be conflicts of interest-that clinicians might have some loyalties not just to the individual patient but to the industry or that the trial might not actually provide optimal personal clinical care. Likewise, the specter of commercial purposes seemed to introduce the notion that clinical research, even when conducted in seemingly legitimate and respected settings, might have goals other than the betterment of humankind.

It is not clear how the disclosure of such information during the consent process might influence participants' decisions to enroll in research studies. For some, such information would not be a deterrent for participation. One person, commenting on how disclosure of commercial purposes could influence future actions noted: "Right off hand, I would say it wouldn't but I may have to reconsider that. I'd have to think about it. I can't come up right of the top of my head with what I'd do. But I am not sure if it would be a decision-breaker. I would be OK with the general concept" (participant 20). Another person explained: "What it would do is tell me that this is a drug that has been around and so maybe my risk would be less. So if I was signing up, I might think I might only be taking a minimal risk. So that would be reassuring. But then the patent issue-well, it would bother me because I would understand the patent game-but most people might not know. You get money for doing something that is low risk and you can do another one. The overall deal is that it is bad for society and good for the person. In the jaded world we know that this is done to make pharms more money" (participant 25). For other participants, however, the specter of commercial purposes would undermine the legitimacy of the study and could become a "deal breaker" in terms of their participation.

The data clearly show that most participants want transparent information about both issues: The potential commercial purposes of research and researcher compensation. The vast majority of participants also felt that it is deceptive not to fully disclose and that forthright information about these issues could certainly influence subsequent 
decisions about research participation. Two comments are illustrative: "Yes. I would ask more questions. If I didn't know that it was available and not disclosed, I would trot along, never suspecting anything. If I knew enough to ask if this was a matter of extending a patent and didn't receive a satisfactory response, I would not go into a study. But I did not know, at the time, to ask the question" (participant 19); and "Yes. Absolutely. To me that is such a direct conflict of interest. It seems a no brainer that you would have to tell people that. I think most people don't understand the structure of how drug testing works and when they are asked to join a study, they wouldn't think to ask questions about stuff like that" (participant 28).

\section{Moving the Conversation Forward}

The findings from the two studies have identified issues that can compromise the protection of human subjects and lend support to the HHS effort to revise the Common Rule. Questions 35 through 40 of the ANPRM seem particularly relevant as they specifically focus on improving informed consent forms, an issue that was an ongoing concern for the IRB members who participated in the authors' study. Question 40 asked whether informed consent would be improved if investigators were required to disclose in consent forms certain information about the financial relationships they have with study sponsors. Our results suggest that research subjects are interested in knowing this information. However, the public comments on this question add another level of complexity to the debate, demonstrating the wide range of opinion on what should, or should not, be disclosed to patients, and the role of IRBs and other committees in reviewing this information (U.S. HHS, 2011). The views expressed suggest that there is currently no consensus on these issues. Some commenters strongly assert that the investigators should be required to disclose in consent forms information about financial relationships they have with study sponsors. One commenter with this perspective wrote: "Researchers and sponsoring Institutions should fully declare all financial and other relationships related to a study and its sponsors to gain and maintain public trust" (Sage Bionetworks, 2011).

In contrast, several comments suggested that research subjects may lack the sophistication to comprehend and assess the significance of potential financial conflicts. One commenter wrote: "The sponsor does not believe that investigators should have to disclose financial relationships with sponsors since subjects are not capable of correctly interpreting this information. This information is already captured in the financial disclosure form and submitted to the FDA at the time of submitting a marketing application" (Boehringer Ingelheim Pharmaceuticals, 2011). Another stated: "No additions to the consent form are recommended. Requiring information about financial relationships is likely to confuse rather than inform subjects about sponsor and investigator relationships" (Fairview Health Services, 2011).

A number of commenters questioned the need for including this requirement, noting that their institution currently requires such disclosure in consent forms, whereas others suggest that including this information in the consent form is not necessary because the vetting of financial conflict of interest is handled by IRBs or conflict of interest committees. As one commenter noted, "We believe institutions should have discretion, but the regulations should not mandate and determine when participants must be notified of financial interests of the investigators. This would be just another administrative burden added to IRB Offices without the hope for or reality of increasing participant protection. Institutions already require their investigators to disclose their financial relationships through their Conflict of Interest committees/process" (Arizona State University, 2011).

Some commenters focused on the complexity of the issue or suggested that no new requirements should be established until research is done to determine the need or importance of such disclosures. One commenter with this perspective stated: "Any proposed additional elements to be included as part of the informed consent process, such as when financial interests of investigators should be disclosed to research subjects, should only be 
considered after further study of what form of interaction is most comprehensible to research subjects" (University of Pittsburgh, 2011).

These comments, when combined with the authors' findings, attest to the challenges that face any effort to meaningfully revise the Common Rule. The data from the IRB and the research participant studies show that the IRB efforts to achieve protection via the best possible consent document are consistently moderated by both the IRB processes and the decision-making process that the research participants bring to the research enterprise. Even the most carefully designed forms may be of limited utility as research participants seem to overlook information in the consent form and instead largely base their decisions on a pervasive level of trust-trust of the one who suggests participation (trusted physician), trust in the system (safe and not allowed if dangerous), trust in the product (new gold standard), and trust in the outcome (personal and humanitarian good). The HHS comments from researchers, administrators, and individuals with commercial interests in research suggest wide discrepancies among the various stakeholders' viewpoints on the effectiveness of current protocols and what may be important going forward. It is critical to hear more from the one voice less well represented by the public comments - that of the research participant. The limited input offered from the perspective of the research participant may represent an important gap in knowledge, as findings from the research participant study suggest that participants have distinct views, perspectives, and concerns on what constitutes full and informed consent.

Although the qualitative design of this research limits the generalizability of findings, it has identified themes, concerns, concepts, and approaches that are relevant to discussions about the protection of human research subjects. To truly identify areas where protection and informed consent can be enhanced, we need to think deeply about the IRB's mission including management of the explicit goal of protecting human subjects and the implicit goals of protecting the interests of researchers and advancing meritorious science. We also need to better understand the values, beliefs, and the expectations that participants bring to their decisions about research participation and whether other information, such as information about researcher compensation or the reason for conducting the study, may be pivotal for the participant's decision making. We need to better understand what researchers and administrators deem effective, reasonable and doable. In short, we need to continually ask ourselves how we can best hear all of the voices who are involved in the research enterprise - those who have a financial, institutional, or professional stake and those who put their health and well-being on the line on behalf of science. The benefits of such inclusive conversations could be considerable; greater awareness and understanding among key stakeholders may reinforce trust and confidence in the research enterprise and ultimately lead to a more ethically attuned research environment, one in which the participant becomes not just protected but informed, and not just a subject but a partner.

\section{References}

Arizona State University (Debra Murphy Director Office of Research Integrity and Assurance). (2011, October 26). Comment on: Human subject research protections: Enhancing protections for research subjects and reducing burden, delay, and ambiguity for investigators [letter]. Retrieved from: http:/ / www.regulations.gov/\#!documentDetail;D=HHSOPHS-2011-0005-0965

Bodenheimer, T. (2000). Uneasy alliance-clinical investigators and the pharmaceutical industry. New England Journal of Medicine, 342, 1539-1544.

Boehringer Ingelheim Pharmaceuticals, Inc. (Dr. Joanne Palmisano, Vice President, Drug Regulatory Affairs). (2011, October 14). Comment on: Human subject research protections: Enhancing protections for research subjects and reducing burden, delay, and ambiguity for investigators [letter]. Retrieved from: http:/ / www.regulations.gov /\#!documentDetail;D=HHSOPHS-2011-0005-0420

Chen, D. T., Miller, F. G., \& Rosenstein, D. L. (2003). Clinical research and the physician-patient relationship. Annals of Internal Medicine, 138, 669.

Christensen, J. A., \& Orlowski, J. P. (2005, May-June). Bounty-hunting and finder's fees. IRB: Ethics in Human Research, 16-19. 
Congressional Budget Office. (2006). A CBO study: Research and development in the pharmaceutical industry. Chapter 2. Washington, DC: Author.

Cook, A. F., \& Hoas, H. (2011a). Exploring the obligation to inform: Disclosing the purpose and benefits of research in an increasingly commercial research environment. American Journal of Bioethics-Primary Research-AJOB$P R, 2(1), 34-41$.

Cook, A. F., \& Hoas, H. (2011b). Protecting research subjects: IRBs in a changing research landscape. IRB Ethics and Behavior, 35,14-19.

Cook, A, F., \& Hoas, H. (2011c). Trading places: What the research participant can tell the investigator about informed consent. Journal of Clinical Research and Bioethics, 2, 1-7.

Hall, M. A., Weinfurt, K. P., Lawlor, J. S., Friedman, J. K., Schulman, K. A., \& Sugarman, J. (2009, JanuaryFebruary). Community hospital oversight of clinical investigators' financial relationships. IRB: Ethics in Human Research, 7-12.

Fairview Health Services (Adrienne Baranauskas, System Director, Research Administration). (2011, October). Comment on: Human subject research protections: Enhancing protections for research subjects and reducing burden, delay, and ambiguity for investigators [letter]. Retrieved from: http:/ / www.regulations.gov/\#!documentDetail;D=HHSOPHS-2011-0005-0895

Fisher, J. A. (2006). Co-ordinating ethical clinical trials: The role of research coordinators in the contract research industry. Sociology of Health and Illness, 28, 678-694.

Fisher, J. A. (2007). Ready to recruit or ready to consent populations? Qualitative Inquiry, 13, 875-894.

Jansen, L. (2005, July-August). Local IRBs, multi-center trials, and the ethics of internal amendments. IRB: Ethics in Human Research, 7-11.

Klein, J. E., \& Fleischman, A. R. (2002, July-August). The private practicing physician investigator: Ethical implications of clinical research in the office setting. Hastings Center Report, 22-26.

Kottow, M. (2009). Clinical and research ethics as moral strangers. Archives of Immunology and Experimental Therapy 57, 157-164.

Macklin, R. (2008, May-June). How independent are IRBs? IRB: Ethics in Human Research, 16.

Miles, M. B., \& Huberman, A. M. (1994). Qualitative data analysis, 2nd edition. Thousand Oaks, CA: Sage.

National Cancer Institute. (2009). Clinical trials cooperative group program. Retrieved from http:// www.cancer.gov/ cancertopics / factsheet/NCI/ clinical-trials-cooperative-group

Nader, R., \& Love, J. (1993). Federally funded pharmaceutical inventions. Testimony before the Special Committee on the Aging of the United States Senate,
February 24. Retrieved from: http:/ / www.cptech.org/ pharm/pryor.html

Sage Bionetworks. (2011, October). Sage Bionetworks submission on proposed common rule changes [letter]. Retrieved from: http://www. regulations.gov /\#!documentDetail;D=HHSOPHS-2011-0005-1053

Sox, H. (2001). Sponsorship, authorship and accountability. Annals of Internal Medicine, 135, 463-466.

Shuchman, M. (2007). Commercializing clinical trialsRisks and benefits of the CRO boom. New England Journal of Medicine, 357, 1356-1368.

Strauss, A. L. \& Corbin, J. M. (1990). Basics of qualitative research: Grounded theory procedures and techniques. Thousand Oaks, CA: Sage.

U.S. Department of Health \& Human Services (U.S. HHS). (2011). Human subjects research protections: enhancing protections for research subjects and reducing burden, delay, and ambiguity for investigators. Retrieved from: http://www.hhs.gov/news/ press/2011pres/07/20110722a.html

United States Senate. (2000). The benefits of medical research and the role of the NIH. Available at: http:/ / www.faseb.org/portals/0/pdfs/opa/2008/ nih_research_benefits.pdf

University of Pittsburgh (Randy P. Juhl, Vice Chancellor). (2011, October 26). Common rule ANPRM comments [letter]. Retrieved from: http://www. regulations.gov/\#!documentDetail;D=HHSOPHS-2011-0005-0823 